\title{
Medical treatment decision making after total avulsion brachial plexus injury: a qualitative study
}

\author{
Lauren E. Franzblau, BS, ${ }^{1}$ Mallory Maynard, BS, ${ }^{1}$ Kevin C. Chung, MD, MS, ${ }^{1}$ \\ and Lynda J.-S. Yang, MD, PhD² \\ ${ }^{1}$ Section of Plastic Surgery, Department of Surgery; and 'Department of Neurosurgery, University of Michigan, \\ Ann Arbor, Michigan
}

OBJECT Complete avulsion traumatic brachial plexus injuries (BPIs) can be treated using nerve and musculoskeletal reconstruction procedures. However, these interventions are most viable within certain timeframes, and even then they cannot restore all lost function. Little is known about how patients make decisions regarding surgical treatment or what impediments they face during the decision-making process. Using qualitative methodology, the authors aimed to describe how and why patients elect to pursue or forego surgical reconstruction, identify the barriers precluding adequate information transfer, and determine whether these patients are satisfied with their treatment choices over time.

METHODS Twelve patients with total avulsion BPIs were interviewed according to a semi-structured guide. The interview transcripts were qualitatively analyzed using the systematic inductive techniques of grounded theory to identify key themes related to the decision-making process and long-term satisfaction with decisions.

RESULTS Four decision factors emerged from our analysis: desire to restore function, perceived value of functional gains, weighing the risks and costs of surgery, and having concomitant injuries. Lack of insurance coverage (4 patients), delayed diagnosis ( 3 patients), and insufficient information regarding treatment (4 patients) prevented patients from making informed decisions and accessing care. Three individuals, all of whom had decided against reconstruction, had regrets about their treatment choices.

CONCLUSIONS Patients with panplexus avulsion injuries are missing opportunities for reconstruction and often not considering the long-term outcomes of surgery. As more Americans gain health insurance coverage, it is very likely that the number of patients able to pursue reconstruction will increase. The authors recommend implementing clinical pathways to help patients meet critical points in care within the ideal timeframe and using a patient- and family-centered care approach combined with patient decision aids to foster shared decision making, increase access to information, and improve patient satisfaction with decisions. These measures could greatly benefit patients with BPI while reducing costs, improving efficiency, and generating better outcomes.

http://thejns.org/doi/abs/10.3171/2015.2.JNS132686

KEY WORDS brachial plexus injury; medical treatment decision making; patient education; peripheral nerve

$\mathrm{T}$ OTAL avulsion traumatic brachial plexus injury (BPI) is a sudden event with lasting physical, psychological, and socioeconomic implications. Surgical management options consist of nerve reconstruction, functioning free-muscle transfer (FFMT), joint fusion, and/ or amputation. Timing determines whether these options are available to a patient (Table 1). ${ }^{1,5,17,33}$ Only nerve reconstruction and muscle transfers can restore functionality and/or protective sensation, but even these do not usually restore adequate arm function. Although these procedures have been studied intensely from technical and objective standpoints, much less is known regarding patient preferences and long-term outcomes. It is unclear how patients decide if surgery is appropriate and advantageous for them, whether they are sufficiently informed to make this choice, and if they are satisfied with their decisions over time.

The traumatic nature of BPI complicates diagnosis and treatment, often delaying what would ideally be an expeditious process. Motor vehicle accidents account for over $70 \%$ of all traumatic BPIs and often lead to other serious injuries that require immediate attention..$^{5,6,17,22,23}$ As a result, many patients present or are diagnosed late and miss

ABBREVIATIONS BPI = brachial plexus injury; FFMT = functioning free-muscle transfer; $P F C C=$ patient- and family-centered care .

ACCOMPANYING EDITORIAL See pp 1411-1412. DOI: 10.3171/2014.5.JNS141012.

SUBMITTED December 5, 2013. ACCEPTED February 19, 2015.

INCLUDE WHEN CITING Published online April 3, 2015; DOI: 10.3171/2015.2.JNS132686.

DISCLOSURE The authors report no conflict of interest concerning the materials or methods used in this paper or the findings specified in this paper. 
TABLE 1. Surgical procedures for total avulsion BPI

\begin{tabular}{llll}
\hline \multicolumn{1}{c}{ Treatment } & \multicolumn{1}{c}{ Indications } & Goals & Ideal Timing \\
\hline FFMT & $\begin{array}{c}\text { Intact intercostal nerves or spinal accessory nerves; } \\
\text { presence of one or both gracilis muscles }\end{array}$ & $\begin{array}{l}\text { Restoration of elbow flexion-extension and/ } \\
\text { or hand function }\end{array}$ & $>9-12$ mos since injury \\
\hline Nerve reconstruction & $\begin{array}{c}\text { Some or all transferrable nerves intact } \\
\text { Restoration of elbow flexion-extension and/ } \\
\text { or protective sensation }\end{array}$ & $<6$ mos since injury \\
\hline Amputation & $\begin{array}{l}\text { Elective procedure; all attempts to restore func- } \\
\text { tion have failed, or patient elects not to pursue } \\
\text { reconstruction }\end{array}$ & Remove flail arm & No limit \\
\hline
\end{tabular}

the opportunity to pursue nerve transfers. 5,6,17,22,23 Aside from timing and injury issues, other factors affecting patient medical decisions are absent from the literature. These are critical decisions with life-long implications for the small but meaningful number of patients who are injured annually, yet little is known about how and why patients choose surgical intervention and what barriers exist in obtaining information and care. Moreover, most studies omit eligible individuals who decide against surgery, which underrepresents their perspectives in the literature.

Many studies have demonstrated that shared decision making, a model defined by mutual exchange and collaboration, can improve patient outcomes, satisfaction with decisions, and compliance with care by fostering choices that align with a patient's personal values. Shared decision making is especially effective in scenarios with more than one "reasonable" choice and/or when making long-term decisions, such as in the management of complete avulsion BPIs: ${ }^{11,14,21}$ however, it cannot be implemented until the current state of the decision-making process is understood. Therefore, the purpose of this study was to qualitatively investigate and describe the decision-making process of patients with diagnosed total avulsion traumatic BPI. In areas lacking adequate exploration, qualitative research can provide more comprehensive insight into the context and meaning of phenomena than the quantitative measures that are used to test hypotheses experimentally. ${ }^{15,38}$ Specifically, we aimed to identify important factors in patient decisions concerning surgical reconstruction, unexplored issues and inadequacies in the current process, and whether patients are satisfied with their choices years afterward.

\section{Methods}

The University of Michigan Institutional Review Board approved all parts of this study. Written informed consent was obtained from all participants.

\section{Study Design}

We used qualitative research methods to better understand themes pertaining to the treatment decision-making process of patients with total avulsion BPI. Qualitative research is both inductive and interpretive, making it useful in yielding contextual information about poorly understood health care topics.,15,16,25,29,31 Our qualitative method included the use of the grounded theory, an approach that develops research themes as data are analyzed, as opposed to defining these themes prior to conducting a study. ${ }^{25,31,40}$ Because treatment decision making for total avulsion BPI is poorly understood, a qualitative methodology promotes the exploration of emotional and experimental phenomena at play in the treatment decision-making process. ${ }^{15,16,25,29,31}$

\section{Setting and Participants}

Unlike quantitative studies that utilize random sampling to achieve statistical power and prove predetermined hypotheses, qualitative studies sample smaller subpopulations that possess relevant study characteristics. ${ }^{4,15,31,32}$ Grounded theory-based investigation of medical decision making among adolescents with neonatal BPIs, patients with tetraplegia, and patients with chronic pain included 18, 22, and 13 subjects, respectively. ${ }^{10,13,35}$ In the present study we screened 163 patients with traumatic BPIs that had been evaluated by 2 surgeons at a large academic health center between 2002 and 2012 (Fig. 1). Of these patients, 23 had complete avulsion injuries and fit our other inclusion criteria: age $>18$ years, no other condition affecting the upper extremities, and no BPI surgery within the past year. These patients were contacted via mail and phone. Twelve chose to participate, 5 were unreachable, 4 declined to join the study, and 2 were unable to participate due to health problems.

\section{Data Collection}

Data collection and analysis followed grounded theory methodology.4,15,16,25,29,31 One research assistant conducted open-ended face-to-face interviews with each participant. The interviewer used a semi-structured interview guide that focused on injury mechanism, initial care and diagnosis, what treatment options were presented, how patients obtained information about care, how decisions about treatment were made, and whether patients were currently satisfied with their decisions. All interviews were audio recorded, allowing the research assistant to form a conversational connection with each participant. Recordings were transcribed verbatim. We obtained objective information about injury and treatment from patient medical records.

\section{Data Analysis}

Two of the research staff meticulously reviewed the transcripts and independently coded themes encountered 
163 Patients with traumatic BPI evaluated from 2002-2012

\section{0 excluded}

- Not complete (C5-T1) avulsion

- Under 18 years

- Health conditions affecting their upper extremity

- Had BPI surgery within the past year

\section{Eligible patients contacted via mail and phone}

\section{5 patients unreachable, 4} declined, 2 unable to participate due to health reasons

\section{2 participants}

FIG. 1. Flowchart illustrating the patient screening and exclusion process.

in the data (that is, open coding). They met periodically to discuss their findings and to develop a codebook of themes organized by categories, codes, and subcodes. Once they coded all transcripts, the reviewers applied the codebook to a portion of the data and reconvened to discuss discrepancies and refine the codebook. When the codebook was finalized, they applied the codes once more to all of the transcripts to examine the frequency of each theme (that is, selective coding) and to select representative quotations to include in this article.

\section{Results}

Of the 12 patients with total avulsion traumatic BPI who participated in this study, all were male and 10 had been injured in motor vehicle accidents. The mean age was 37 years (range 25-66 years; Table 2). Interviews lasted an average of 47 minutes. Fig. 2 illustrates themes relating to medical decision making as a conceptual framework, corresponding to patient experiences. We discuss each cat-
TABLE 2. Demographic data, injury factors, and treatment in 12 men with BPI

\begin{tabular}{ll}
\hline \multicolumn{1}{c}{ Variable } & No. \\
\hline Mean age in years (range) & $37(25-66)$ \\
\hline Mean time since injury in years (range) & $7.8(2.3-24)$ \\
\hline Trauma (\%) & $5(42)$ \\
\hline Motorcycle accident & $2(17)$ \\
\hline Snowmobile accident & $3(25)$ \\
\hline Other motor vehicle accident & $2(17)$ \\
\hline Fall/sports injury & \\
\hline Concomitant injuries (\%) & $5(42)$ \\
\hline Scapula, clavicle, rib fractures & $4(33)$ \\
\hline Vertebra fracture & $4(33)$ \\
\hline Lower extremity fracture & $3(25)$ \\
\hline Upper extremity fracture & $3(25)$ \\
\hline Traumatic brain injury/coma & $2(17)$ \\
\hline None & $1(8)$ \\
\hline Skull fracture & \\
\hline Surgical treatment (\%) & $4(33)$ \\
\hline Single FFMT & $2(17)$ \\
\hline Double FFMT & $1(8)$ \\
\hline Nerve transfer & $1(8)$ \\
\hline Amputation & $4(33)$ \\
\hline None & $11 \dagger(5-228)$ \\
\hline Time to surgery in mos (range) &
\end{tabular}

* Percentages do not add up to $100 \%$ because of rounding.

† Mean excludes 1 patient who had surgery 19 years after injury.

egory (sources of information about injury and treatment, decision factors, obstacles to care, and long-term satisfaction with decision) in depth below. Representative quotations for each theme can be found in Table 3.

\section{Sources of Information About Injury and Treatment}

Patients reported using 3 sources of information about diagnosis and treatment (Fig. 3): doctors (12 patients), online research (5 patients), and media (3 patients). Although physicians provided the most thorough explanations and facts, 6 participants reported receiving poor or no information about their diagnoses or treatment options at smaller hospitals. In an extreme case, 1 individual diagnosed his condition after requesting his medical records and researching his symptoms on the Internet. The other 4 participants who conducted their own research used it to supplement the information provided by their doctors. The media was misleading because it portrayed fictitious interventions using stem cells and lasers that patients hoped would become available in the future.

\section{Decision Factors}

Although restoring function was the initial concern of all participants, 3 other themes (perceived value of functional gains, risks and costs of surgery, and presence of concomitant injuries) were critical to deciding whether to 


\author{
Sources of Information about Injury and Treatment \\ Doctors \\ Online Research \\ Media
}

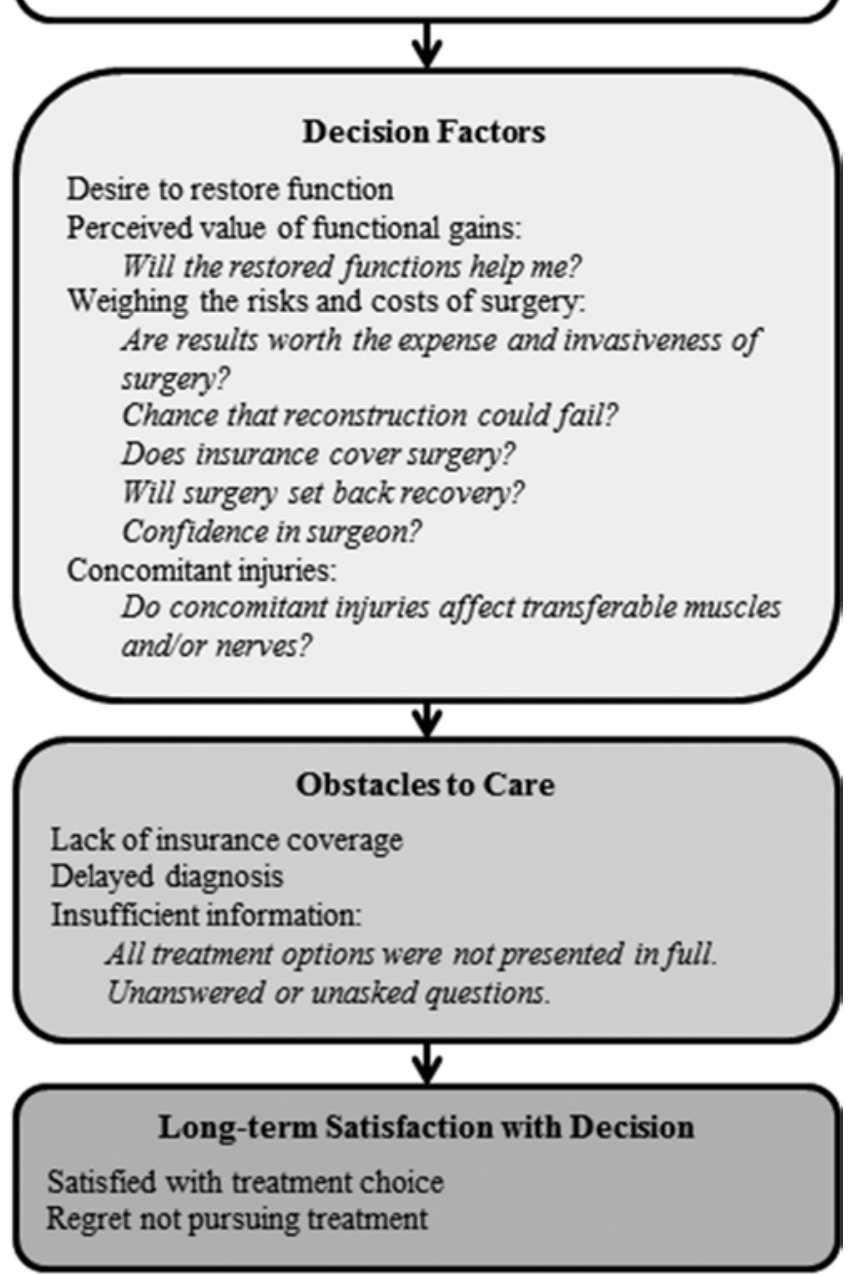

FIG. 2. Conceptual framework of medical decision-making process with themes.

pursue surgical reconstruction (Fig. 3). Six believed that the functionality achieved through reconstruction was disappointing and/or not worth the costs and risks associated with surgery. One of these individuals ultimately decided that "in the long run" the restored functions would be important to him, and he decided to pursue FFMT; the remaining 5 did not seek reconstruction. These patients stressed the insignificance of the gains (3 patients), the chance that the operation would fail ( 3 patients), and a reluctance to set back their recovery ( 3 patients). Three patients had serious concomitant injuries that delayed their decision regarding reconstruction and increased their reluctance to reenter the hospital. One patient chose amputation; he decided against reconstruction because it did not seem "viable" given the chance of failure and because he believed he "might get more use out of a prosthetic" than he had with a flail arm.
For the 7 patients who underwent reconstruction (FFMT 6; nerve transfer 1), functional gains were the main motivator behind their decisions. As a group, these participants believed that having surgery and prolonging recovery were worth the risk because there was a chance to regain some amount of function. All of these patients had health insurance that covered FFMT and/or nerve transfer and believed that this was a critical factor in pursuing reconstruction.

\section{Obstacles to Care}

Lack of insurance coverage (4 patients), delayed diagnosis (3 patients), and insufficient information (4 patients) reduced the number of treatment options available to patients and hindered them in making informed decisions about their care (Fig. 3). Those who were not told about reconstruction initially were first treated at smaller rural medical centers, where FFMT and nerve transfer were not available. Seven participants regretted not asking certain questions and still desired answers about what exactly a nerve avulsion injury means, why it cannot be "fixed," and/or what options exist.

\section{Long-Term Satisfaction With Decision}

Nine patients reported being satisfied with their decisions about treatment (Table 4). Interestingly, 2 patients who underwent FFMT and were dissatisfied with their outcomes still were happy that they had pursued surgery. The 3 participants who expressed regret about their decisions had chosen not to have reconstruction; 2 were disappointed that they were not informed about reconstruction until the opportunity had passed, and 1 regretted dismissing nerve transfer when it was presented to him.

\section{Discussion}

The goal of this study was to qualitatively assess and describe how patients with complete avulsion BPIs navigate decisions about reconstruction and whether they are satisfied with their choices over time, and to identify the issues that exist with the current status of medical decision making in this patient group. Through examining the experiences of 12 patients, we identified 3 obstacles to care (late diagnosis, inadequate information, and lack of insurance coverage) and 4 factors in patient decision making concerning whether to pursue reconstruction (desire to improve function, perceived value of functional gains, weighing the risks and costs of surgery, and concomitant injuries). Seven patients chose reconstruction and were satisfied with their decisions; 5 elected not to undergo reconstruction, and 3 of them had regrets about their choice.

Late diagnosis and failure to receive information regarding treatment options were both major obstacles to informed decision making and accessing care. In our sample, 3 patients received a late diagnosis, 4 reported being inadequately informed at the time they made their decisions, and 7 still had unanswered questions. These findings suggest that the current system of diagnosing, referring, and treating patients should be improved. Developing a BPI clinical pathway and strengthening communication between smaller hospitals and interdisciplinary specialty centers for BPI care could help to facilitate timely referral and 
TABLE 3. Selected excerpts from patient interviews representative of decision-making themes

\begin{tabular}{|c|c|c|}
\hline Theme & Quote & Respondent Attributes \\
\hline \multirow[t]{3}{*}{ Information sources } & $\begin{array}{l}\text { "As soon as they told me what it was, I had to know about it, so I researched } \\
\text { everything I could about it." }\end{array}$ & $\begin{array}{l}26 \text { yo, no treatment, } 2.5 \text { years } \\
\text { postinjury }\end{array}$ \\
\hline & $\begin{array}{l}\text { "I just don't quite understand [what my injury is] and when the doctor did try to } \\
\text { explain it to me, I had a hard time understanding him." }\end{array}$ & $\begin{array}{l}35 \text { yo, no treatment, } 13 \text { years postin- } \\
\text { jury }\end{array}$ \\
\hline & $\begin{array}{l}\text { "They [the doctors] presented so much that I really felt like there were no more } \\
\text { questions...I knew exactly what I was getting into." }\end{array}$ & 25 yo 2 FFMT, 4.3 years postinjury \\
\hline $\begin{array}{l}\text { Perceived value of } \\
\text { functional gains }\end{array}$ & $\begin{array}{l}\text { "I'd at least be able to hold a cup or a glass of water and I was like, well that'd be } \\
\text { great. If I could hold onto something... l'd figure out all kinds of ways with stuff." }\end{array}$ & 48 yo, 1 FFMT, 10 years postinjury \\
\hline \multirow[t]{2}{*}{$\begin{array}{l}\text { Weighing the risks and } \\
\text { costs of surgery }\end{array}$} & $\begin{array}{l}\text { "How much of a big surgery it was going to be... with minimal gain, it wouldn't be } \\
\text { worth it." }\end{array}$ & $\begin{array}{l}26 \text { yo, no treatment, } 2.5 \text { years } \\
\text { postinjury }\end{array}$ \\
\hline & $\begin{array}{l}\text { "I figured if it could get me any use or better my function in any way that it would } \\
\text { be worth doing." }\end{array}$ & 34 yo, 1 FFMT, 3.8 years postinjury \\
\hline Concomitant injuries & "The biggest factor was how damaged the muscles were in my legs." & $\begin{array}{l}26 \text { yo, no treatment, } 2.5 \text { years } \\
\text { postinjury }\end{array}$ \\
\hline \multirow[t]{2}{*}{$\begin{array}{l}\text { Factors related to } \\
\text { amputation }\end{array}$} & $\begin{array}{l}\text { "Either cut it off or keep holding on to it and hoping they'll come up with something } \\
\text { stem cell research." }\end{array}$ & $\begin{array}{l}35 \text { yo, no treatment, } 13 \text { years postin- } \\
\text { jury }\end{array}$ \\
\hline & $\begin{array}{l}\text { "When it became more of a hazard and hindrance than a point of having it as a } \\
\text { piece of meat I decided to go ahead and have it amputated.... I decided I might } \\
\text { be better off with a prosthetic than an arm." }\end{array}$ & $\begin{array}{l}66 \text { yo, amputation and shoulder fu- } \\
\text { sion, } 8.5 \text { years postinjury }\end{array}$ \\
\hline \multirow[t]{2}{*}{ Late diagnosis } & $\begin{array}{l}\text { "I didn't find out [I had a BPI] until I [obtained] my medical records and started } \\
\text { reading them. I figured it out." }\end{array}$ & 48 yo, 1 FFMT, 10 years postinjury \\
\hline & $\begin{array}{l}\text { "They didn't know what was wrong. So they took another MRI there and they still } \\
\text { didn't know what was wrong. So they took me to [another] hospital...I took } \\
\text { about } 4 \text { MRIs at [the second hospital]. And that's when a dude came up to me } \\
\text { and said we have never seen an injury like this before." }\end{array}$ & 26 yo, 2 FFMT, 2.5 years postinjury \\
\hline Insufficient information & $\begin{array}{l}\text { "They've never told me I could get it fixed. They really didn't give me much } \\
\text { information besides it was paralyzed and I was never gonna be able to use it } \\
\text { again. [Actually] they told me one time. It was last year when I came back, like } \\
11 \text { years later, for a checkup." }\end{array}$ & $\begin{array}{l}35 \text { yo, no treatment, } 13 \text { years postin- } \\
\text { jury }\end{array}$ \\
\hline $\begin{array}{l}\text { Satisfaction with treat- } \\
\text { ment decision }\end{array}$ & $\begin{array}{l}\text { "I'm happy about having the surgery, but also l'm really not satisfied about the } \\
\text { outcomes so far." }\end{array}$ & 27 yo, 1 FFMT, 24 years postinjury \\
\hline Regret & $\begin{array}{l}\text { "Looking back I wish I had taken the time to research it myself and...dug a little } \\
\text { deeper than just say no...just that percentage she threw out there kind of } \\
\text { turned my mind off to it." }\end{array}$ & 56 yo, no treatment, 7 years postinjury \\
\hline
\end{tabular}

yo $=$ years old

treatment while reducing the number of patients who miss the opportunity for primary nerve reconstruction. Clinical pathways, also called "critical pathways," are condition- or procedure-specific sequential care plans involving multiple specialties that increase efficiency and reduce costs while improving quality of care. ${ }^{12,18,19}$ This sort of planning is ideal for BPI management, which requires coordinated multidisciplinary care within a specific timeframe. Espinosa-Aguilar et al. ${ }^{12}$ report the development and validation of a clinical pathway for patients with traumatic brain injuries who, like patients with BPI, are typically young men injured in motor vehicle accidents. This pathway, in particular, may be a useful guide for smaller and rural hospitals because it was designed for areas with limited resources.

In order for a clinical pathway to succeed, patients need to be directed to treatment centers via a sound referral system. Traumatic BPI referral patterns and timing are largely unknown. In a study from Ireland, the median time from injury to referral was 8.2 months, already outside the window for nerve transfer, and $51 \%$ of patients with a diagnosis of traumatic BPI were not referred to the national brachial plexus service for treatment. ${ }^{9}$ The median injury-to-surgery time interval was 9 months in our study and 12 months in another study from the United States, which suggests that delays in treatment similar to those in Ireland exist here in the United States. ${ }^{3}$ Establishing clear lines of communication and referral between referring and receiving hospitals will help to ensure that patients are informed of and have access to all reconstructive options within the optimal timeframes. Furthermore, trauma centers should be aware that BPIs occur in roughly $1.2 \%$ of all multiple trauma patients, with a greater incidence $(4 \%-5 \%)$ in victims of gunshot wounds, motorcycle accidents, and snowmobile accidents. Certain other injuries, including head injuries and scapular, clavicular, and humeral fractures, are also associated with BPI. ${ }^{26}$ 
Sources of Information

Decision Factors

Obstacles to Care

Long-term Satisfaction with Decision

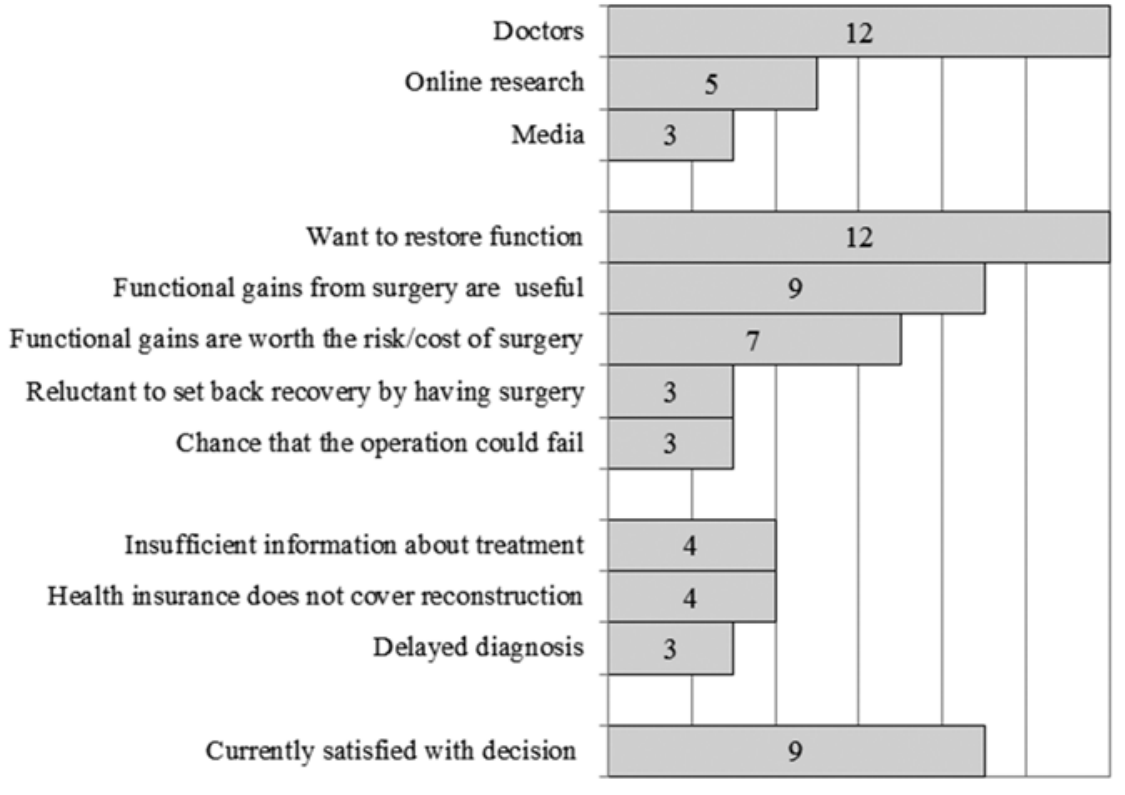

FIG. 3. Summary of patient responses to questions concerning sources of information, decision factors, obstacles to care, and long-term satisfaction with their decision.

Although a lack of health insurance coverage for brachial plexus reconstruction was a barrier to participants in our study, it is very likely that more patients will have health insurance that enables them to pursue reconstruction. Since the passing of the Affordable Care Act in 2010, the percentage of uninsured Americans has decreased significantly for young adults, who are most often affected by traumatic BPIs. ${ }^{33,34}$ Among 19- to 25 -year-olds visiting emergency departments, the proportion with private insurance increased by $5 \%$ and the proportion with no insurance decreased by $4.5 \%$ from 2009 to $2011 .{ }^{27}$ Although the lack of health insurance coverage is not completely resolved, it is probable that more patients will be motivated to pursue reconstructive surgery for complete avulsion BPI as insurance coverage expands. All participants who chose to undergo FFMT or nerve transfer named health insurance coverage as a critical factor in their decisions.

During the decision-making process, however, patients in our study focused primarily on immediate factors rather than lasting effects. Only 1 patient recalled specifically considering the long-term outcomes of surgery. In contrast, 3 patients referred to a reluctance to extend their recovery by undergoing surgery. Although appreciable, the desire to be discharged from the hospital and to expe-

TABLE 4. Patient satisfaction with treatment decision stratified by treatment group

\begin{tabular}{lcccc}
\hline \multicolumn{1}{c}{ Variable } & FFMT & $\begin{array}{c}\text { Nerve } \\
\text { Transfer }\end{array}$ & $\begin{array}{c}\text { No } \\
\text { Surgery }\end{array}$ & Amputation \\
\hline Total no. of patients & 6 & 1 & 4 & 1 \\
\hline $\begin{array}{c}\text { Currently satisfied } \\
\text { with decision }\end{array}$ & 6 & 1 & 1 & 1 \\
\hline Has regrets & 0 & 0 & 3 & 0 \\
\hline
\end{tabular}

dite recovery from the initial trauma may prevent patients from fully considering how their injuries and reconstruction could affect the rest of their lives. Three of 4 patients who decided against reconstruction had regrets about this choice at the time of our study. Patients with BPIs, like patients in our study, have serious concomitant injuries that can keep them in the hospital for weeks or months before brachial plexus treatment can be pursued. ${ }^{22,26}$ Coordinating the management of multiple injuries may make it difficult for patients to invest themselves fully in making each choice and could explain why 7 participants in the present study still had unanswered questions about their care. Multiple methods exist to foster patient participation in shared decision making, which is preferred by the majority of adults in the United States. ${ }^{28}$

Patient- and family-centered care (PFCC) is one such method; it is a practice model that strives to provide safe, effective, patient-centered, efficient, and equitable care in a timely manner.,20,25,30,37 To meet these goals, practitioners, patients, and families enter into a partnership defined by open sharing of information and cooperation to ensure that medical decisions align with a patient's goals and values and are evidence based. ${ }^{7}$ By involving family members who may offer a valuable, more objective perspective, PFCC could help patients with BPI to consider long-term outcomes that may not seem important during the initial intensive recovery process. Furthermore, the close collaboration of specialists and fortified support network of family and doctors could improve the treatment process. Patient- and family-centered care has been shown to improve outcomes while decreasing costs. ${ }^{8}$ DiGioia et al..$^{7,8}$ presented 4 approaches to integrating PFCC into practice based on their experience at the University of Pittsburgh Medical Center, which began in the orthopedics department and has since spread to 60 other clinics. 
The development of written patient education materials, such as decision aids, could further increase patient participation in decision making and considering all relevant factors, helping to reduce missed opportunities for treatment as a result of insufficient information. Patient decision aids have been shown to increase patient knowledge and the accuracy of risk perceptions, reduce decisional conflict due to poor information and/or a lack of clarity about personal values, and increase the proportion of patients who are active in decision making. ${ }^{36}$ Greater understanding of one's condition and participation in decision making are also linked to better health outcomes, and written materials, in particular, are associated with greater retention of information. ${ }^{2,24,40}$ By facilitating open discussions of patient goals for treatment and helping patients to identify important issues, a decision aid could help to reduce misunderstanding and decisional conflict and lead to greater satisfaction with decisions. ${ }^{20,25,30,37}$ It could also enhance the delivery of PFCC because patients can take home written materials and discuss them with their families.

Several limitations to our study should be recognized. Most notable is the small and homogeneous sample. Although we were limited by the availability of patients, we believe that 12 participants were sufficient to qualitatively explore themes in the decision-making process; no new concepts were emerging by the end of our analysis, indicating that we had reached the saturation point. The response rate was low but not unexpected. Similarly low response rates have been reported in other qualitative studies. ${ }^{1,39}$ Complete avulsion BPI is a rare injury that is treated at Level I trauma centers. Many eligible patients do not live nearby, and others have moved since being treated and thus were unreachable. Selection bias toward individuals who had more positive experiences may have also influenced our sample. To make all patients feel comfortable participating, we informed them during recruitment that this study was separate from their clinical care and offered a wide range of dates and times for study appointments.

As with all qualitative research, the subjectivity of investigators and recall bias of participants can affect the findings. To minimize investigator bias, 2 members of the research staff analyzed data independently and came to a consensus on any discrepancies in their coding. Because our purpose was to describe long-term patient satisfaction as well as decision making, we do not believe that recall bias was a major limitation. Brachial plexus injuries have life-long effects, and it is important to understand whether patients are satisfied with their initial treatment decisions over time.

\section{Conclusions}

Brachial plexus injuries are traumatic events, and it is ultimately up to the patient to decide whether he or she wants to undergo another physically difficult experience like surgical reconstruction. However, it is imperative for physicians to educate patients about every treatment option and to encourage them to consider how each option fits with their long-term goals, so that patients can make careful, informed decisions without future regret. Our study identified a number of problems with the current decision-making process, including delayed diagnosis, insufficient information in the community, and lack of insurance coverage. Further exploration of these issues is necessary to determine their extent. However, the development of clinical pathways, PFCC models, and a patient decision aid for traumatic BPIs would greatly benefit patients facing the choice of surgical reconstruction and, if made publicly available, could expand access to information beyond interdisciplinary specialty BPI referral centers.

\section{References}

1. Aravind M, Shauver MJ, Chung KC: A qualitative analysis of the decision-making process for patients with severe lower leg trauma. Plast Reconstr Surg 126:2019-2029, 2010

2. Arora NK, McHorney CA: Patient preferences for medical decision making: who really wants to participate? Med Care 38:335-341, 2000

3. Barrie KA, Steinmann SP, Shin AY, Spinner RJ, Bishop AT: Gracilis free muscle transfer for restoration of function after complete brachial plexus avulsion. Neurosurg Focus 16(5):E8, 2004

4. Beaton DE, Clark JP: Qualitative research: a review of methods with use of examples from the total knee replacement literature. J Bone Joint Surg Am 91 (Suppl 3):107-112, 2009

5. Belzberg AJ, Dorsi MJ, Storm PB, Moriarity JL: Surgical repair of brachial plexus injury: a multinational survey of experienced peripheral nerve surgeons. J Neurosurg 101:365-376, 2004

6. Choi PD, Novak CB, Mackinnon SE, Kline DG: Quality of life and functional outcome following brachial plexus injury. J Hand Surg Am 22:605-612, 1997

7. DiGioia A III, Greenhouse PK, Levison TJ: Patient and family-centered collaborative care: an orthopaedic model. Clin Orthop Relat Res 463:13-19, 2007

8. DiGioia AM III, Fann MN, Lou F, Greenhouse PK: Integrating patient- and family-centered care with health policy: four proposed policy approaches. Qual Manag Health Care 22:137-145, 2013

9. Dolan RT, Butler JS, Hynes DE, Cronin KJ: The nerve to delay: the impact of delayed referrals in the management of traumatic brachial plexus injuries in the Republic of Ireland. J Plast Reconstr Aesthet Surg 65:1127-1129, 2012

10. Dunn JA, Hay-Smith EJ, Whitehead LC, Keeling S: Liminality and decision making for upper limb surgery in tetraplegia: a grounded theory. Disabil Rehabil 35:1293-1301, 2013

11. Elwyn G, Frosch D, Thomson R, Joseph-Williams N, Lloyd A, Kinnersley P, et al: Shared decision making: a model for clinical practice. J Gen Intern Med 27:1361-1367, 2012

12. Espinosa-Aguilar A, Reyes-Morales H, Huerta-Posada CE, de León IL, López-López F, Mejía-Hernández M, et al: Design and validation of a critical pathway for hospital management of patients with severe traumatic brain injury. $\mathbf{J}$ Trauma 64:1327-1341, 2008

13. Fenwick C, Chaboyer W, St John W: Decision-making processes for the self-management of persistent pain: a grounded theory study. Contemp Nurse 42:53-66, 2012

14. Flynn D, Knoedler MA, Hess EP, Murad MH, Erwin PJ, Montori VM, et al: Engaging patients in health care decisions in the emergency department through shared decisionmaking: a systematic review. Acad Emerg Med 19:959-967, 2012

15. Giacomini MK, Cook DJ, Evidence-Based Medicine Working Group: Users' guides to the medical literature: XXIII. Qualitative research in health care A. Are the results of the study valid? JAMA 284:357-362, 2000 
16. Giacomini MK, Cook DJ, Evidence-Based Medicine Working Group: Users' guides to the medical literature: XXIII. Qualitative research in health care B. What are the results and how do they help me care for my patients? JAMA 284:478-482, 2000

17. Giuffre JL, Kakar S, Bishop AT, Spinner RJ, Shin AY: Current concepts of the treatment of adult brachial plexus injuries. J Hand Surg Am 35:678-688, 2010 (Erratum in J Hand Surg Am 35:1226, 2010)

18. Harkleroad A, Schirf D, Volpe J, Holm MB: Critical pathway development: an integrative literature review. Am J Occup Ther 54:148-154, 2000

19. Ignatavicius DD, Hausman KA: Clinical Pathways for Collaborative Practice. Philadelphia: Saunders, 1995

20. Johnson BH: The changing role of families in health care. Child Health Care 19:234-241, 1990

21. Joosten EA, DeFuentes-Merillas L, de Weert GH, Sensky T, van der Staak CP, de Jong CA: Systematic review of the effects of shared decision-making on patient satisfaction, treatment adherence and health status. Psychother Psychosom 77:219-226, 2008

22. Kaiser R, Mencl L, Haninec P: Injuries associated with serious brachial plexus involvement in polytrauma among patients requiring surgical repair. Injury 45:223-226, 2014

23. Kretschmer T, Ihle S, Antoniadis G, Seidel JA, Heinen C, Börm W, et al: Patient satisfaction and disability after brachial plexus surgery. Neurosurgery 65 (4 Suppl):A189-A196, 2009

24. Levinson W, Kao A, Kuby A, Thisted RA: Not all patients want to participate in decision making. A national study of public preferences. J Gen Intern Med 20:531-535, 2005

25. Mays N, Pope C: Qualitative research in health care. Assessing quality in qualitative research. BMJ 320:50-52, 2000

26. Midha R: Epidemiology of brachial plexus injuries in a multitrauma population. Neurosurgery 40:1182-1189, 1997

27. Mulcahy A, Harris K, Finegold K, Kellermann A, Edelman L, Sommers BD: Insurance coverage of emergency care for young adults under health reform. N Engl J Med 368:21052112,2013

28. Murray E, Pollack L, White M, Lo B: Clinical decisionmaking: patients' preferences and experiences. Patient Educ Couns 65:189-196, 2007

29. Pope C, Ziebland S, Mays N: Qualitative research in health care. Analysing qualitative data. BMJ 320:114-116, 2000

30. Rangachari P, Bhat A, Seol YH: Using the "customer service framework" to successfully implement patient- and familycentered care. Qual Manag Health Care 20:179-197, 2011
31. Shauver MJ, Chung KC: A guide to qualitative research in plastic surgery. Plast Reconstr Surg 126:1089-1097, 2010

32. Shauver MS, Aravind MS, Chung KC: A qualitative study of recovery from type III-B and III-C tibial fractures. Ann Plast Surg 66:73-79, 2011

33. Shin AY, Spinner RJ, Steinmann SP, Bishop AT: Adult traumatic brachial plexus injuries. J Am Acad Orthop Surg 13:382-396, 2005

34. Sommers BD, Kronick R: The Affordable Care Act and insurance coverage for young adults. JAMA 307:913-914, 2012

35. Squitieri L, Larson BP, Chang KW, Yang LJ, Chung KC: Medical decision-making among adolescents with neonatal brachial plexus palsy and their families: a qualitative study. Plast Reconstr Surg 131:880e-887e, 2013

36. Stacey D, Bennett CL, Barry MJ, Col NF, Eden KB, HolmesRovner M, et al: Decision aids for people facing health treatment or screening decisions. Cochrane Database Syst Rev (10):CD001431, 2011

37. Stewart M, Brown JB, Donner A, McWhinney IR, Oates J, Weston WW, et al: The impact of patient-centered care on outcomes. J Fam Pract 49:796-804, 2000

38. Strauss AL, Corbin JM: Basics of Qualitative Research: Techniques and Procedures for Developing Grounded Theory, ed 2. Thousand Oaks, CA: Sage Publications, 1998

39. Wain HR, Kneebone II, Billings J: Patient experience of neurologic rehabilitation: a qualitative investigation. Arch Phys Med Rehabil 89:1366-1371, 2008

40. Walker JA: What is the effect of preoperative information on patient satisfaction? Br J Nurs 16:27-32, 2007

\section{Author Contributions}

Conception and design: Yang, Maynard. Acquisition of data: all authors. Analysis and interpretation of data: all authors. Drafting the article: Yang, Franzblau, Maynard. Critically revising the article: all authors. Reviewed submitted version of manuscript: all authors. Approved the final version of the manuscript on behalf of all authors: Yang. Study supervision: Yang, Chung.

\section{Correspondence}

Lynda J. S. Yang, Department of Neurosurgery, University of Michigan, 1500 E. Medical Center Dr., 3552 Taubman Center, Ann Arbor, MI 48109-5338. email: ljsyang@med.umich.edu. 